\title{
A multi-product inventory management model in a three-level supply chain with multiple members at each level
}

\author{
Saeed Ghourchiany and Morteza Khakzar Bafrouei*
}

Department of Industrial Engineering, Technology Development Institute (ACECR), Tehran, Iran

\begin{tabular}{l}
\hline C H R O N I C L E \\
\hline Article history: \\
Received December18, 2017 \\
Accepted April 202018 \\
Available online \\
April 202018 \\
\hline Keywords: \\
Supply chain management \\
Three-level supply chain \\
Inventory management
\end{tabular}

Article history:

Received December18, 2017

Available online

Keywords:

Three-level supply chain

Inventory management

\begin{abstract}
A B S T R A C T
In this paper, a mathematical model for multi-product inventory management in a three-tier supply chain consisting of multi-supplier, a manufacturer, and several retailers is presented. The model determines different factors such as the optimum ordering of the raw materials and the optimal level of the production items with the optimal order of the products by retailers at each level of the chain, with the objective of minimizing inventory management costs in the supply chain. An algorithm is presented to determine the solution of the problem and the implementation of the proposed method is demonstrated using some numerical example.
\end{abstract}

(C) 2019 by the authors; licensee Growing Science, Canada

\section{Introduction}

In recent years, an integrated assessment of the suppliers, producers, distributors and consumers that make up the supply chain components is one of the areas that has received much attention (Pandey et al., 2017; Rastogi et al., 2017; Shah, 2017; Tripathi \& Kaur, 2017). From an operational point of view, supply chain management integrates suppliers, builders, warehouses and storage facilities in a manner that is effective in producing and distributing goods at the right time and in the right place, and maintaining the total cost of the system while maintaining the appropriate level of service to the customers (Glock, 2012). On the other hand, inventory management is one of the most important elements in the supply chain, because a significant amount of the assets of companies lies in the amount of their inventory, so the issues related to inventory management with the goal of minimizing the total cost of the chain and the cost of the finished product is of great importance (Glock et al., 2014).

Today, researchers are paying a lot of attention to the development of inventory management issues for multi-level supply chains, given that many products, such as electrical goods, food products and pharmaceuticals, and the automotive industry, are produced at the factory, while the raw materials are provided from different locations, so the coordination of suppliers of raw materials, manufacturers and retailers in a supply chain plays an essential role for the success of the firms (Pal et al., 2012, 2014).

* Corresponding author

E-mail address: khakzar@jdsharif.ac.ir (M. Khakzar Bafruei)

(C) 2019 by the authors; licensee Growing Science, Canada doi: $10.5267 /$ j.uscm.2018.4.001 
Below is a brief overview of some related studies conducted on inventory management models in supply chains with more than two levels, and supply chains with more than a few members per level. Kumar and Kumar (2016) investigated the effect of learning and salvage worth on an inventory model for deteriorating items with inventory-dependent demand rate and partial backlogging with capability constraints. Mashud et al. (2018) studied a non-instantaneous inventory model having various deterioration rates with stock and price dependent demand under partially backlogged shortages. Banerjee and Kim (1995) presented one of the first integrated models that reviewed the inventory management of more than two members in the supply chain, in which they ordered the procurement of raw materials in the supply chain with a buyer, a producer, and a supplier. The expansion of this model was presented by Lee (2005), who analyzed the raw material orders in the supply chain, and, contrary to the previous model, he assumed that the manufacturer had the possibility of ordering as much as one-half the size of his production to the supplier and able to satisfy the own demand with several orders during the preparation and at different intervals. Banerjee et al. (2007) extended the older work published by Banerjee and Kim (1995), where the supply chain inquiry involves several buyers, and each buyer receives a stock at the same time intervals by the same sender. A similar system of multisupplier, manufacturer, and multi-buyer was also been analyzed by Jaber and Goyal (2008), which assumes that suppliers provide different components of the product to the manufacturer where the manufacturer assembles those components and produces the final product. In this research, the buyer's order cycle time is considered the same. The development of this problem can be found in the Sarker and Diponegoro's (2009) model, which considers only one product in the chain, and assumes that the subsequent production cycles can be of different sizes, hence the system's flexibility has increased, leading to reduce the total system costs.

Kim et al. (2006) proposed a modified version of the problem and examined a system that includes a vendor that provides several different products for multiple buyers. For the ordering of raw materials in the seller's part, it is assumed that different items are produced for each buyer with a tool. Another related problem has been studied by Chen and Chen (2005), the authors assumed that the buyer ordered several products for the producer, and the products were produced with the same production tool under the same quality, although a general preparation at the beginning of the cycle production is required, and, at the same time, minor preparations must be made to change from one product to another. In order to save on the cost of preparing an inventory replacement program for all products, it could be helpful to show that this program would reduce the total cost of the system. Chen and Chen (2007) and Chen et al. (2010) expanded the model to include parameters such as price-sensitive demand and deterioration of the products. The existence of multiple production equipment in the production sector has been analyzed by Kim et al. (2005), and their model focused on a raw material supplier, a producer and a buyer. The problem was determining the ordered cycles, production, and production allocations for producers. The expanded model of this issue, which includes several products, is in Kim and Hong (2008), where distributors who are intermediaries between the seller and the buyer are also considered by Wee and Yang (2004), in which a delivery vendor the products are distributed to several distributors and distributors are responsible for supplying products to each buyer. The assumption is that the periods of product loading in the buyer area are less than the reload period in the distributor's part, and this period in the distributor is also less than the reload period in the vendor's part. Another variant of this model was proposed by Abdul Jabbar et al. (2007), which focuses on a supplier of raw materials, a vendor and two buyers. Compared to Wee and Yang (2004), reload intervals in each buyer are allowed to be larger than the reload intervals in the vendor, so more flexibility is added to the model, which helps to maintain different costs for buyers and the seller should be considered.

Chung (2008) considered a supply chain consisting of a supplier, a producer, a retailer and a supplier of damaged items, and a model that maximizes the overall system profit. This model was developed by Yang et al. (2007), in which several cycles of production and re-production were added to the model. Seliaman (2008) considered a multi-stage chain with a supplier and assumed that each member of the chain could have multiple applicants at their lower levels. Sarker and Balan (1999) investigated a multi- 
level supply chain in which there is a linear function for demand and production rates, Pal et al. (2012) considered a three layer multi-item production-inventory model for multiple suppliers and retailers. Wang and Sarker (2006) modeled and solved a multi-level supply chain model assuming that it is not possible to defect, Wang and Sarker (2005) examined a generalized supply chain of montage, using an innovative algorithm based on branch and bound method to use to solve it. Roy et al. (2012) modeled and solved the three-level supply chain with random demand and the possibility of deficiency, Pal et al. (2014) considered a multi-level supply chain with the potential of disturbing supply of raw materials and disturbing product modeling.

\section{The proposed study}

Some papers presented in the context of multi-level and multi-member supply chains were examined. In this paper, development strategies for inventory management models for three-tier supply chains are considered, the issue considers inventory management of a three-level chain and a few products, and the main components of this chain include the supplier sector, a manufacturer and retailer, in which the supply chain of each supplier is responsible for supplying one of the components or raw materials, and after sending the parts to the part production, the percentage composition of the components and raw materials are turned into finished products and sent to retailers. In this model, in addition to determining the optimal amount of raw material order, the optimal amount of the production and optimal order of retailers are also determined. In this paper, an initial mathematical model of inventory management is presented. In order to determine the optimal problem solution, an innovative algorithm is used. At the end, numerical examples of the problem are implemented, the schematic representation of this problem is shown in Fig. 1.

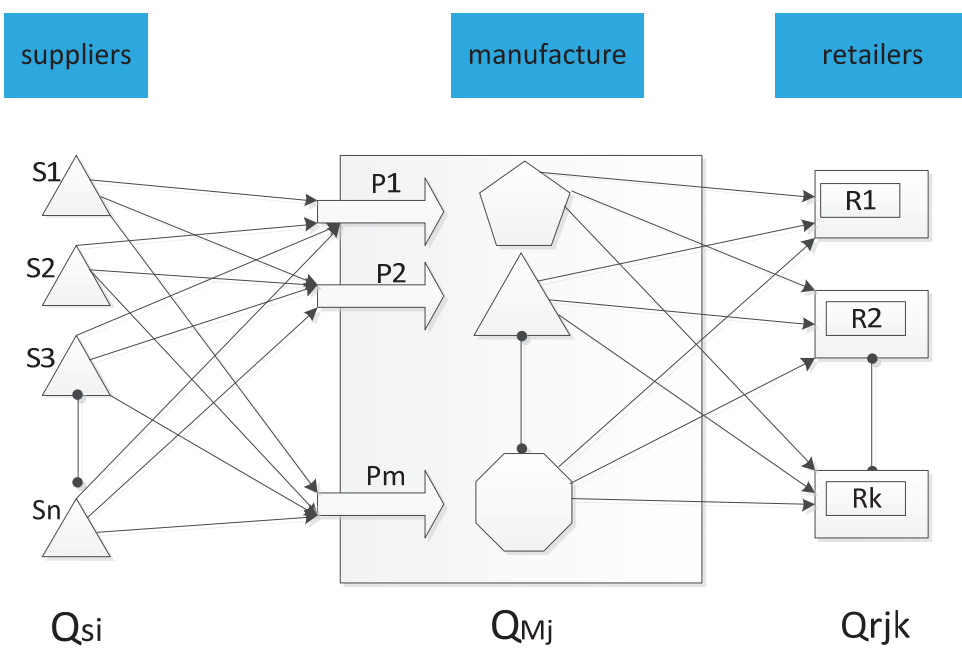

Fig. 1. The structure of the proposed study

\subsection{Assumptions}

As stated, the proposed study considers an inventory management of a three-tiered and multi-product chain, and the main components of this chain are multi-supplier, manufacturer, and multi-retailer, and the following assumptions are considered for this issue.

- The problem is considered as a multi-product and integrated management of inventory of products at different levels of the chain, simultaneously.

- It is assumed that each supplier is solely responsible for supplying one component or raw material. 
- In this case, $n$ parts are received from the suppliers and in the production sector, they are converted into $m$ final products, and the products are sent to $k$ retailers, eventually each product is delivered to a specific customer.

- The amount of demand in each level is considered known.

- Delivery times between suppliers, manufacturers and retailers are negligible.

- There is no shortage.

Details of the target functions, constraints and problem variables at each level of the chain are as follows,

- The objective function of the problem is to minimize the cost for the entire chain in an integrated manner.

- The decision variables include the optimal order quantity of each product in the retailer, the optimal production rate of each product in the manufacturer's part, and the optimal order quantity of each of the primary components in the supplier's part.

- Retail costs are the cost of purchasing from the manufacturer, the cost of ordering, and the cost of maintaining the products.

- The costs of the manufacturer's part are the cost of purchasing the product, the cost of preparing the product and the cost of maintaining the products.

- The costs of the supplier's part include the purchase price, the ordering cost and the cost of maintaining the raw materials.

- Maintenance, preparation and ordering costs are different at each level of the chain and the horizons are considered indefinitely.

\section{Variables}

$h_{s i} \quad$ The cost of holding the raw materials for the supplier $i$

$C_{s i} \quad$ The cost of purchasing raw material from the supplier $i$

$T_{s i} \quad$ Time period for consuming raw materials from the supplier $i$

$D_{s i} \quad$ Request for the original supplier of the $i$

$Q_{s i} \quad$ The order quantity of supplier $i$

$\alpha_{i j} \quad$ Percentage of raw material used from supplier $i$ to produce product $j$

$I_{i} \quad$ The average of raw materials of the supplier $i$

$A C S_{i} \quad$ Average cost of inventory per unit time for the supplier's $i$

$A C S \quad$ Average inventory costs per unit time for all suppliers

$P_{j} \quad$ Production rate of product $j$

$h_{m j} \quad$ The holding cost of the $j$-th product for the manufacturer's side

$I_{j} \quad$ Average inventory of product $j$

$T_{m j} \quad$ Period of production and consumption of product $\mathrm{j}$ in the manufacturer's side

$t_{m j} \quad$ Period of production of the product $j$ in the manufacturer's part

$C P_{j} \quad$ Production cost per unit of product $j$

$D_{m j} \quad$ Demand for product $j$

$p_{j} \quad$ The production rate of product $j$ in the manufacturer's side

$Q_{m j} \quad$ The amount of production of the product $j$ in the manufacturer's part

$A C M_{j} \quad$ Average costs of inventory of $j$ th product per unit time in the manufacturer

$A C M$ Average cost of inventory per unit time in the manufacturer's part

$D_{c j k} \quad$ The final customer demand of the $k$-th retailer for the $j$ th product

$h_{r k j} \quad$ The holding cost of the product $j$ for the $k$-th retailer

Trkj The period of the $j$ product for the $k$-th retailer

$D_{r k j} \quad$ The demand for product $j$ in the retail chain

$Q_{r k j} \quad$ order quantity in retailer side 
$A C R_{k}$ The average cost of inventory per unit time in the retail chain $k$

$A C R \quad$ Average inventory costs per unit time for all retailers

$A C T$ Average inventory costs per unit time for the entire chain

$K_{r} \quad$ Frequency of orders for delivery of raw materials in the supplier's side

$m_{j} \quad$ The frequency of sending the $j$-th product to retailers in a production cycle

$f_{j} \quad$ The frequency of sending the $j$-th product to retailers when they produce a production cycle

$n_{i} \quad$ The frequency of sending the $i$-th raw material in each supplier's order cycle

$Z \quad$ Dimensional matrix of variables in the Hsian matrix of the target function

$\lambda \quad$ Eigenvalue

The level of inventory in the supplier's part number $i$ at any time is as shown in Fig. 2.

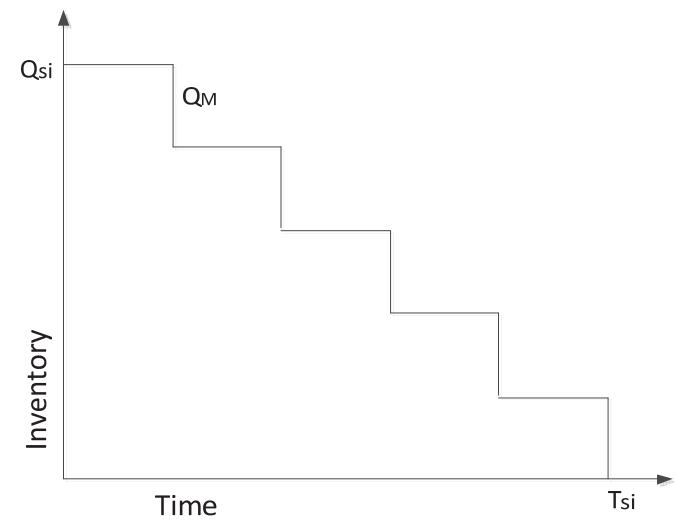

Fig. 2. Material inventory chart in the supplier's part

The inventory costs in the supplier's side include the purchase, order, and inventory costs, as determined below.

The cost of purchasing the raw material by the supplier $i$

$$
\mathrm{C}_{\mathrm{si}} \mathrm{Q}_{\mathrm{si}}
$$

The cost of ordering the raw material by the supplier $i$

$$
A_{\mathrm{si}}
$$

The relationship between the amount of the raw material supplier and the amount of production:

The quantity of the initial material $i$ for each period $n_{i}$ is equal to the total amount of the primary material used in the manufacturer's production side, which is included in the following formula in the model,

$$
Q_{\mathrm{si}}=\sum_{j} n_{i} \alpha_{i j} Q_{m j}
$$

Average inventory of raw material by the supplier $i$ in each period is as follows,

$$
I_{i}=\left(n_{i}+\left(n_{i}-1\right)+\left(n_{i}-2\right)+\cdots+1\right) \sum_{j} \alpha_{i j} Q_{m j}=\frac{T_{s i}}{n_{i}} \frac{1}{2} n_{i}\left(n_{i}+1\right) \sum_{j} \alpha_{i j} Q_{m j}=\frac{1}{2} T_{s i}\left(n_{i}+1\right) \sum_{j} \alpha_{i j} Q_{m j}
$$

Costs of inventory of raw material by the supplier $i$ in each period are as follows,

$$
\frac{1}{2} \mathrm{~h}_{\mathrm{si}} T_{s i}\left(n_{i}+1\right) \sum_{j} \alpha_{i j} Q_{m j}
$$

Total inventory costs per supplier period

$$
\mathrm{C}_{\mathrm{si}} \mathrm{Q}_{\mathrm{si}}+A_{\mathrm{si}}+\frac{1}{2} \mathrm{~h}_{\mathrm{si}} T_{s i}\left(n_{i}+1\right) \sum_{j} \alpha_{i j} Q_{m j}
$$


Average cost of inventory per unit time for the $i$ th supplier:

$$
A C S_{i}=\mathrm{C}_{\mathrm{si}} \frac{\mathrm{Q}_{\mathrm{si}}}{T_{s i}}+\frac{1}{T_{s i}} A_{\mathrm{si}}+\frac{1}{2} \mathrm{~h}_{\mathrm{si}}\left(n_{i}+1\right) \sum_{j} \alpha_{i j} Q_{m j}
$$

Average inventory costs per unit time for all suppliers

$$
A C S=\sum_{i}\left(\mathrm{C}_{\mathrm{si}} \frac{\mathrm{Q}_{\mathrm{si}}}{T_{s i}}+\frac{1}{T_{s i}} A_{\mathrm{si}}+\frac{1}{2} \mathrm{~h}_{\mathrm{si}}\left(n_{i}+1\right) \sum_{j} \alpha_{i j} Q_{m j}\right)
$$

Modeling inventory system for the manufacturer side:

The level of inventory of the product $j$ in the manufacturer at any time is in accordance with Fig. 3.

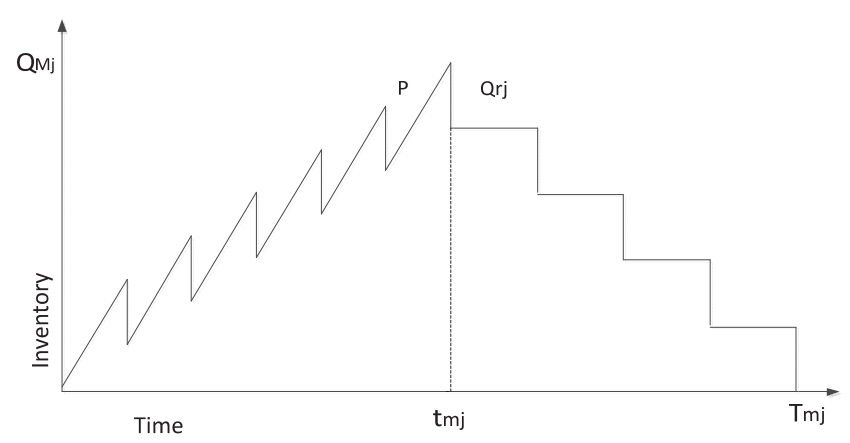

Fig. 3. The level of inventory for product $j$

The cost of preparing the production of $j$

$$
A_{\mathrm{mj}}
$$

Average product inventory j per course

In determining the average inventory, it is necessary to determine the ratio of the frequency of sending products at the time of production of $f_{j}$ to the number of deliveries of products $m_{j}$, which is determined in accordance with Eq. (9) as follows,

$$
\begin{aligned}
& Q_{m j}=p_{j} t_{m j}=p_{j} \frac{f_{j}}{m_{j}} T_{m j}=p_{j} \frac{f_{j}}{m_{j}} \frac{Q_{m j}}{D_{m j}} \\
& \frac{f_{j}}{m_{j}}=\frac{D_{m j}}{p_{j}}
\end{aligned}
$$

The area of the inventory is determined as follows,

$$
\begin{aligned}
& I_{j}=\frac{1}{2} p_{j}\left(t_{m j}\right)^{2}-\left(1+2+\cdots+f_{j}-1\right) \sum_{1}^{k} Q_{r j k} \frac{T_{m j}}{m_{j}}+p_{j} t_{m j}\left(T_{m j}-t_{m j}\right)-\left(f_{j}+f_{j}+1+\cdots+m_{j}-1\right) \sum_{1}^{k} Q_{r j k} \frac{T_{m j}}{m_{j}} \\
& =p_{j} t_{m j}\left(T_{m j}-\frac{1}{2} t_{m j}\right)-\left(1+2+\cdots+m_{j}-1\right) \sum_{1}^{k} Q_{r j k} \frac{T_{m j}}{m_{j}} \\
& =p_{j} \frac{Q_{m j}}{p_{j}}\left(1-\frac{1}{2} \frac{D_{m j}}{p_{j}}\right) T_{m j}-\frac{1}{2}\left(m_{j}-1\right) \sum_{1}^{k} Q_{r j k} T_{m j} \\
& =Q_{m j}\left(1-\frac{1}{2} \frac{D_{m j}}{p_{j}}\right) T_{m j}-\frac{1}{2}\left(m_{j}-1\right) \sum_{1}^{k} Q_{r j k} T_{m j}
\end{aligned}
$$


The cost of maintaining the inventory of the $j$ th product in a period is as follows,

$$
I_{j} h_{m j}=Q_{m j}\left(1-\frac{1}{2} \frac{D_{m j}}{p_{j}}\right) h_{m j} T_{m j}-\frac{h_{m j}}{2}\left(m_{j}-1\right) \sum_{1}^{k} Q_{r j k} T_{m j}
$$

Cost of inventory of $\mathrm{j}$ product per unit time:

$$
Q_{m j}\left(1-\frac{1}{2} \frac{D_{m j}}{p_{j}}\right) h_{m j}-\frac{h_{m j}}{2}\left(m_{j}-1\right) \sum_{1}^{k} Q_{r j k}
$$

Relationship between the quantity of raw material and the quantity of production in the manufacturer's side is as follows,

$$
Q_{s i}=\sum_{j} \alpha_{i j} n_{i} Q_{m j}=\sum_{j} \alpha_{i j} n_{i} m_{j} Q_{r j k}
$$

Cost per unit of product $\mathrm{j}$ is as follows,

$$
C_{P j}
$$

Total inventory costs of the $j$ th product in a period of time for the manufacturer's side:

$$
C_{P j} Q_{m j}+A_{\mathrm{mj}}+Q_{m j}\left(1-\frac{1}{2} \frac{D_{m j}}{p_{j}}\right) h_{m j} T_{m j}-\frac{h_{m j}}{2}\left(m_{j}-1\right) \sum_{1}^{k} Q_{r j k} T_{m j}
$$

Total cost of inventory of $j$ th product per unit time in the manufacturer's side is as follows,

$$
A C M_{j}=C_{p j} \frac{Q_{m j}}{T_{m j}}+\frac{1}{T_{m j}} A_{m j}+Q_{m j}\left(1-\frac{1}{2} \frac{D_{m j}}{p_{j}}\right) h_{m j}-\frac{h_{m j}}{2}\left(m_{j}-1\right) \sum_{1}^{k} Q_{r j k}
$$

Total inventory costs of all products per unit time in the manufacturer's part:

$$
A C M=\sum_{j}\left(C_{\mathrm{pj}} \frac{Q_{m j}}{T_{m j}}+\frac{1}{T_{m j}} A_{\mathrm{mj}}+Q_{m j}\left(1-\frac{1}{2} \frac{D_{m j}}{p_{j}}\right) h_{m j}-\frac{h_{m j}}{2}\left(m_{j}-1\right) \sum_{1}^{k} Q_{r j k}\right.
$$

\section{Retail inventory system modeling:}

The level of inventory of the $j$ product is at the retail level of $k$ at any time in accordance with Fig. 4 .

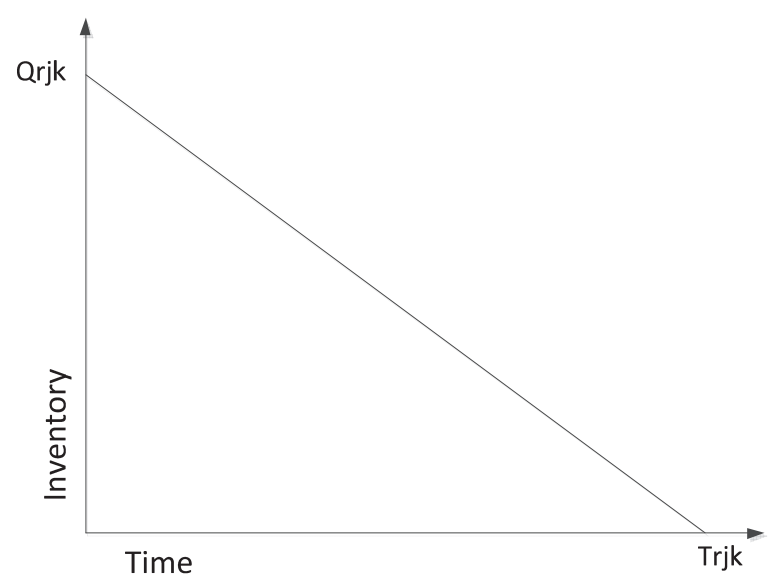

Fig. 4. The product level of $j$ is in the retail chain $k$ 
Cost of purchasing the $j$-th product in retail $k$

$$
C_{r \mathrm{jk}} \mathrm{Q}_{r \mathrm{jk}}
$$

The cost of ordering the $j$-th product in the retailer's $k$ :

$$
A_{\text {rjk }}
$$

Inventory of inventory of $j$ products in $k$ th retail department:

$$
\frac{1}{2} \mathrm{~h}_{r \mathrm{jk}} \mathrm{Q}_{r \mathrm{jk}} T_{r \mathrm{jk}}
$$

Total inventory costs of the $j$ product in a cycle in the retailer $k$ :

$$
A C R_{j k}=C_{r \mathrm{jk}} \mathrm{Q}_{r \mathrm{jk}}+A_{r \mathrm{jk}}+\frac{1}{2} \mathrm{~h}_{r \mathrm{jk}} \mathrm{Q}_{r \mathrm{jk}} T_{r \mathrm{jk}}
$$

Total cost of inventory of $j$ th product per unit time in retail chain $k$ :

$$
A C R_{j k}=\mathrm{C}_{r \mathrm{jk}} D_{r \mathrm{jk}}+\frac{D_{r \mathrm{jk}}}{\mathrm{Q}_{r \mathrm{jk}}} A_{r \mathrm{jk}}+\frac{1}{2} \mathrm{~h}_{r \mathrm{jk}} \mathrm{Q}_{r \mathrm{jk}}
$$

Total inventory costs per unit time for all retailers

$$
A C R=\sum_{k} \sum_{j}\left(\mathrm{C}_{r \mathrm{jk}} D_{r \mathrm{jk}}+\frac{D_{r \mathrm{jk}}}{\mathrm{Q}_{r \mathrm{jk}}} A_{r \mathrm{jk}}+\frac{1}{2} \mathrm{~h}_{r \mathrm{jk}} \mathrm{Q}_{r \mathrm{jk}}\right)
$$

Total chain cost is as follows,

$$
\begin{aligned}
& \mathrm{ACT}=A C S+A C M+A C R=\sum_{\mathrm{i}}\left(\mathrm{C}_{\mathrm{si}} \frac{\mathrm{Q}_{\mathrm{si}}}{\mathrm{T}_{\mathrm{si}}}+\frac{1}{\mathrm{~T}_{\mathrm{si}}} \mathrm{A}_{\mathrm{si}}+\frac{1}{2} \mathrm{~h}_{\mathrm{si}}\left(\mathrm{n}_{\mathrm{i}}+1\right) \sum_{\mathrm{j}} \alpha_{\mathrm{ij}} \mathrm{Q}_{\mathrm{mj}}\right)+\sum_{\mathrm{j}}\left(\mathrm{C}_{\mathrm{mj}} \frac{\mathrm{Q}_{\mathrm{mj}}}{\mathrm{T}_{\mathrm{mj}}}+\right. \\
& \frac{1}{\mathrm{~T}_{\mathrm{mj}}} \mathrm{A}_{\mathrm{mj}}+Q_{m j}\left(1-\frac{1}{2} \frac{D_{m j}}{p_{j}}\right) h_{m j}-\frac{h_{m j}}{2}\left(m_{j}-1\right) \sum_{1}^{k} Q_{r j k}+\sum_{k} \sum_{j}\left(\mathrm{C}_{r \mathrm{jk}} D_{r \mathrm{jk}}+\frac{D_{r \mathrm{jk}}}{\mathrm{Q}_{r \mathrm{jk}}} A_{r j \mathrm{k}}+\frac{1}{2} \mathrm{~h}_{r \mathrm{jk}} \mathrm{Q}_{r \mathrm{jk}}\right)
\end{aligned}
$$

The optimal production value of the product $j$ in the manufacturer's part is $m_{j}$, is equal to the total order of this product in the retailer, which is determined Eq. (25).

$$
Q_{m j}=m_{j} \sum_{1}^{k} Q_{r j k}
$$

The optimal order quantity of the $i$ th material is equal to $n_{i}$, which is equal to the total order of this material in the manufacturer's side for all products and is determined in accordance with Eq. 26.

$$
Q_{s i}=\sum_{j} \alpha_{i j} n_{i} Q_{m j}=\sum_{j} \alpha_{i j} n_{i} m_{j} \sum_{1}^{k} Q_{r j k}=\sum_{j} \sum_{k} \alpha_{i j} n_{i} m_{j} Q_{r j k}
$$

The amount of demand for product $j$ in the manufacturer's part is equal to the total demand for this product in the retailer, which is determined in accordance with Eq. (27).

$$
D_{m j}=\sum_{k} D_{r j k}
$$

The amount of demand for raw material $i$ is equal to the total amount of use of this material in the manufacturer's as, as determined in accordance with Eq. (28).

$$
D_{s i}=\sum_{j} \alpha_{i j} D_{m j}=\sum_{j} \sum_{k} \alpha_{i j} D_{r j k}
$$

The producer's period of time is determined in accordance with the Eq. (29) as follows,

$$
T_{m j}=\frac{Q_{m j}}{D_{m j}}=\frac{m_{j} \sum_{1}^{k} Q_{r j k}}{\sum_{k} D_{r j k}} .
$$


The producer's period of time is determined in accordance with the Eq. (30) as follows.

$$
T_{s i}=\frac{Q_{s i}}{D_{s i}}=\frac{Q_{s i}}{\sum_{j} \alpha_{i j} D_{m j}}=\frac{\sum_{j} \sum_{k} \alpha_{i j} n_{i} m_{j} Q_{r j k}}{\sum_{j} \sum_{k} \alpha_{i j} D_{r j k}}
$$

By replacing the above relations, the objective function of the problem is determined as follows,

$$
\begin{aligned}
& \left.A C T=\sum_{i}\left(\mathrm{C}_{\mathrm{si}} \sum_{j} \sum_{k} \alpha_{i j} D_{r j k}+\frac{\sum_{j} \sum_{k} \alpha_{i j} D_{r j k}}{\sum_{j} \sum_{k} \alpha_{i j} m_{i} m_{r j k}} A_{\mathrm{si}}+\frac{1}{2} \mathrm{~h}_{\mathrm{si}}\left(n_{i}+1\right) \sum_{j} \sum_{k} \alpha_{i j} m_{j} Q_{r j k}\right)\right)+\sum_{j}\left(\left(C_{\mathrm{mj}} \sum_{k} D_{r j k}+\right.\right. \\
& \left.\left.\frac{\sum_{k} D_{r j k}}{m_{j} \sum_{1}^{k} Q_{r j k}} A_{\mathrm{mj}}+m_{j} \sum_{1}^{k} Q_{r j k}\left(1-\frac{1}{2} \frac{\sum_{k} r_{r j k}}{p_{j}}\right) h_{m j}-\frac{h_{m j}}{2}\left(m_{j}-1\right) \sum_{1}^{k} Q_{r j k}\right)\right)+\sum_{k} \sum_{j}\left(\mathrm{C}_{r j \mathrm{k}} D_{r j \mathrm{k}}+\frac{D_{r j \mathrm{k}}}{Q_{r j \mathrm{k}}} A_{r j \mathrm{k}}+\right. \\
& \left.\frac{1}{2} \mathrm{~h}_{r j \mathrm{k}} \mathrm{Q}_{r \mathrm{jk}}\right)
\end{aligned}
$$

Given that this is an unconstrained non-linear multivariate programming, to solve this problem and to determine its optimal point, the development of the innovative method proposed by the Sarker and Diponegoro (2009), which is presented for the single-product supply chain issue is used.

The proposed method consists of a combination search algorithm that consists of two external loops to determine the variables $m$ and $n$, and the best way to determine the quantity of $Q_{r j k}$ variables within the loops is to use the multi-variable search using the gradient of the target function. The generalization of the solving algorithm explained as follow:

\section{Algorithm}

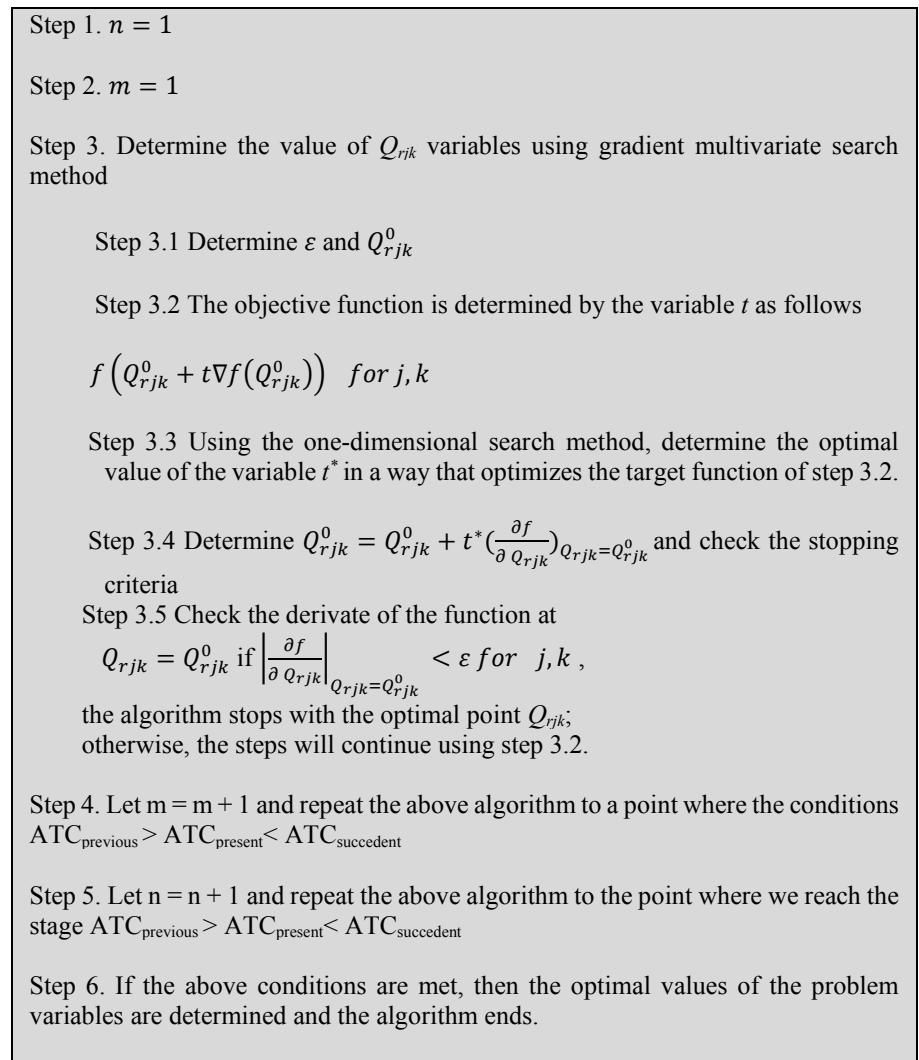

\section{Example}

Consider a supply chain with three suppliers, a manufacturer, and four retailers, for example. In this supply chain, only one primary material is provided and the three primary materials in the manufacturer 
are converted into two final products, and the final products are delivered to the four retailers in terms of their demands. Parameters for each of the supply chain levels are considered in accordance with Table 1.

Table 1

The input information for the example

\begin{tabular}{cccccccccccc}
\hline$A s_{1}$ & $A s_{2}$ & $A s_{3}$ & $h s_{1}$ & $h s_{2}$ & $h s_{3}$ & $c s_{1}$ & $c s_{2}$ & $c S_{3}$ & $c m_{1}$ & $c m_{2}$ & $\mathrm{P}$ \\
26000 & 24800 & 96000 & 10 & 15 & 12 & 600 & 500 & 700 & 2500 & 3000 & 20000 \\
$\theta_{1}$ & $\theta_{2}$ & $\alpha_{11}$ & $\alpha_{21}$ & $\alpha_{31}$ & $\alpha_{12}$ & $\alpha_{22}$ & $\alpha_{32}$ & $A m_{1}$ & $A m_{2}$ & $h m_{1}$ & $h m_{2}$ \\
4 & 8 & 3 & 2 & 1 & 3 & 2 & 5 & 15000 & 18400 & 130 & 150 \\
$c r_{11}$ & $c r_{12}$ & $c r_{13}$ & $c r_{14}$ & $c r_{21}$ & $c r_{22}$ & $c r_{23}$ & $c r_{24}$ & $h r_{11}$ & $h r_{12}$ & $h r_{13}$ & $h r_{14}$ \\
5200 & 5500 & 6210 & 6200 & 6370 & 5360 & 6310 & 5390 & 247 & 352 & 194 & 219 \\
$h r_{21}$ & $h r_{22}$ & $h r_{23}$ & $h r_{24}$ & $A r_{11}$ & $A r_{12}$ & $A r_{13}$ & $A r_{14}$ & $A r_{21}$ & $A r_{22}$ & $A r_{23}$ & $A r_{24}$ \\
185 & 234 & 335 & 442 & 1900 & 7800 & 2490 & 9370 & 4695 & 2850 & 7275 & 1700 \\
$D_{r 11}$ & $D_{r 12}$ & $D_{r 13}$ & $D_{r 14}$ & $D_{r 21}$ & $D_{r 22}$ & $D_{r 23}$ & $D_{r 24}$ & & & & \\
1500 & 2100 & 3000 & 10000 & 7900 & 11800 & 22950 & 33900 & & & \\
\hline
\end{tabular}

Given the numerical parameters of Table 1 and the application of the proposed solution method, the amount of problem variables including the optimal order of each raw material, the optimal amount of product production and the optimal value of the order of final products by retailers, as well as the optimal value of the objective function of the problem are given in Table 2 as follows.

Table 2

The summary of the optimal results

\begin{tabular}{cccccccccc}
\hline$m_{1}$ & $m_{2}$ & $n_{1}$ & $n_{2}$ & $n_{3}$ & $Q_{r 11}$ & $Q_{r 12}$ & $Q_{r 13}$ & $Q_{r 14}$ \\
2 & 5 & 2 & 1 & 1 & 104.24 & 231.62 & 184.69 & 514.42 \\
$Q_{r 21}$ & $Q_{r 22}$ & $Q_{r 23}$ & $Q_{r 24}$ & $Q_{m 1}$ & $Q_{m 2}$ & $Q_{s 1}$ & $Q_{s 2}$ & $Q_{s 3}$ \\
345.83 & 325.71 & 561.44 & 358.76 & 2070 & 7958.7 & 60172 & 20057 & 41863 \\
ATC & & & & & & & & \\
$1.3574 \mathrm{e}+009$ & & & & & & & \\
\hline
\end{tabular}

Note that all eigenvalues of the hessian matrix of the proposed study are positive and we can conclude that the final solution is local minimum.

\section{Conclusion}

In this paper, a mathematical model for the management of three-level supply chain inventory, multicommodity and multiparty development was developed in which a manufacturer uses a combination of raw materials to produce different products. The members of this chain include multi-suppliers, a manufacturer, and several retailers. In this chain, each supplier is only obliged to supply a type of raw material to the manufacturer. For retailers, there is a possibility of ordering each product to the manufacturer, which is the result of the final consumer demand of each product on the market.

In this paper, the demand for each product is considered to be deterministic, as well as the parameters used for storing and ordering final products and raw materials at each level and for each member of the different chain. The objective function of the problem is the aggregate inventory costs of the supplier, the manufacturer, and the retailers. By minimizing this objective function, the problem variables include the amount of raw material ordering suppliers, the amount of each product, and the order of each product for retailers, as well as the optimal amount of the target function. The model is a nonlinear programming model and an innovative algorithm based on the search method and the gradient algorithm was used to solve the problem. An algorithm was used to solve the problem and the implementation is demonstrated by a numerical example. As noted above, since the objective function of this problem is nonlinear, the proof of the convexity of the objective function is not analytically feasible, we have provided some evidence using the eigenvalue of the hessian matrix based on some 
numerical example. For future research, one may consider the problem with uncertainty in demands and other input parameters and we leave it as a future research for interested researchers.

\section{References}

Abdul-Jalbar, B., Gutierrez, J. M., \& Sicilia, J. (2007). An integrated inventory model for the singlevendor two-buyer problem. International Journal of Production Economics, 108(1-2), 246-258.

Banerjee, A., \& Kim, S. L. (1995). An integrated JIT inventory model. International Journal of Operations \& Production Management, 15(9), 237-244.

Banerjee, A., Kim, S. L., \& Burton, J. (2007). Supply chain coordination through effective multi-stage inventory linkages in a JIT environment. International Journal of Production Economics, 108(1-2), 271-280.

Chen, T. H., \& Chen, J. M. (2005). Optimizing supply chain collaboration based on joint replenishment and channel coordination. Transportation Research Part E: Logistics and Transportation Review, 41(4), 261-285.

Chen, J. M., \& Chen, T. H. (2007). The profit-maximization model for a multi-item distribution channel. Transportation Research Part E: Logistics and Transportation Review, 43(4), 338-354.

Chen, J. M., Lin, I. C., \& Cheng, H. L. (2010). Channel coordination under consignment and vendormanaged inventory in a distribution system. Transportation Research Part E: Logistics and Transportation Review, 46(6), 831-843.

Chung, K. J. (2008). A necessary and sufficient condition for the existence of the optimal solution of a single-vendor single-buyer integrated production-inventory model with process unreliability consideration. International Journal of Production Economics, 113(1), 269-274.

Glock, C. H. (2012). The joint economic lot size problem: A review. International Journal of Production Economics, 135(2), 671-686.

Glock, C. H., Grosse, E. H., \& Ries, J. M. (2014). The lot sizing problem: A tertiary study. International Journal of Production Economics, 155, 39-51.

Jaber, M. Y., \& Goyal, S. K. (2008). Coordinating a three-level supply chain with multiple suppliers, a vendor and multiple buyers. International Journal of Production Economics, 116(1), 95-103.

Kim, T., \& Hong, Y. (2008). production allocation, lot-sizing, and shipment policies for multiple items in multiple production lines. International Journal of Production Research, 46(1), 289-294.

Kim, T., Hong, Y., \& Chang, S. Y. (2006). Joint economic procurement-production-delivery policy for multiple items in a single-manufacturer, multiple-retailer system. International Journal of Production Economics, 103(1), 199-208.

Kim, T., Hong*, Y., \& Lee, J. (2005). Joint economic production allocation and ordering policies in a supply chain consisting of multiple plants and a single retailer. International Journal of Production Research, 43(17), 3619-3632.

Kumar, N., \& Kumar, S. (2016). Effect of learning and salvage worth on an inventory model for deteriorating items with inventory-dependent demand rate and partial backlogging with capability constraints. Uncertain Supply Chain Management, 4(2), 123-136.

Lee, W. (2005). A joint economic lot size model for raw material ordering, manufacturing setup, and finished goods delivering. Omega, 33(2), 163-174.

Mashud, A., Khan, M., Uddin, M., \& Islam, M. (2018). A non-instantaneous inventory model having different deterioration rates with stock and price dependent demand under partially backlogged shortages. Uncertain Supply Chain Management, 6(1), 49-64.

Pal, B., Sana, S. S., \& Chaudhuri, K. (2012). A three layer multi-item production-inventory model for multiple suppliers and retailers. Economic Modelling, 29(6), 2704-2710.

Pal, B., Sana, S. S., \& Chaudhuri, K. (2014). A multi-echelon production-inventory system with supply disruption. Journal of Manufacturing Systems, 33(2), 262-276.

Pandey, R., Singh, S., Vaish, B., \& Tayal, S. (2017). An EOQ model with quantity incentive strategy for deteriorating items and partial backlogging. Uncertain Supply Chain Management, 5(2), 135142. 
Rastogi, M., Singh, S., Kushwah, P., \& Tayal, S. (2017). An EOQ model with variable holding cost and partial backlogging under credit limit policy and cash discount. Uncertain Supply Chain Management, 5(1), 27-42.

Roy, A., Sana, S. S., \& Chaudhuri, K. (2012). Optimal replenishment order for uncertain demand in three layer supply chain. Economic Modelling, 29(6), 2274-2282.

Sana, S. S. (2012). A collaborating inventory model in a supply chain. Economic Modelling, 29(5), 2016-2023.

Sarker, B. R., \& Balan, C. V. (1999). Operations planning for a multi-stage kanban system. European Journal of Operational Research, 112(2), 284-303.

Sarker, B. R., \& Diponegoro, A. (2009). Optimal production plans and shipment schedules in a supplychain system with multiple suppliers and multiple buyers. European Journal of Operational Research, 194(3), 753-773.

Seliaman, M. E. (2008). Optimizing inventory decisions in a multi-stage supply chain under stochastic demands. Applied Mathematics and Computation, 206(2), 538-542.

Shah, N. (2017). Retailer's optimal policies for deteriorating items with a fixed lifetime under orderlinked conditional trade credit. Uncertain Supply Chain Management, 5(2), 126-134.

Tripathi, R., \& Kaur, M. (2017). EOQ model for non-decreasing time dependent deterioration and Decaying demand under non-increasing time shortages. Uncertain Supply Chain Management, 5(4), 327-336.

Wang, S., \& Sarker, B. R. (2006). Optimal models for a multi-stage supply chain system controlled by kanban under just-in-time philosophy. European Journal of Operational Research, 172(1), 179200.

Wang, S., \& Sarker, B. R. (2005). An assembly-type supply chain system controlled by kanbans under a just-in-time delivery policy. European Journal of Operational Research, 162(1), 153-172.

Wee, H. M., \& Yang, P. C. (2004). The optimal and heuristic solutions of a distribution network. European Journal of Operational Research, 158(3), 626-632.

Yang, P. C., Wee, H. M., \& Yang, H. J. (2007). Global optimal policy for vendor-buyer integrated inventory system within just in time environment. Journal of Global Optimization, 37(4), 505-511.

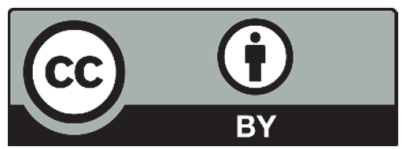

(C) 2019 by the authors; licensee Growing Science, Canada. This is an open access article distributed under the terms and conditions of the Creative Commons Attribution (CC-BY) license (http://creativecommons.org/licenses/by/4.0/). 